\title{
A FORMAÇÃO PLENA DO ENGENHEIRO NAS UNIVERSIDADES, ALÉM DO CÁLCULO: A COMUNICAÇÃO ORAL COMO BASE PARA UM BOM PROFISSIONAL DA ENGENHARIA
}

DOI: 10.37702/2175-957X.COBENGE.2021.3396

Luiz Gustavo Lopes Penna - luizglopes90@gmail.com

Universidade Federal de Itajubá

Rua São Paulo 570

35900-352 - Itabira - MG

MOACYR ALVES BRETAS LAGE - moacyrl@hotmail.com

Universidade Federal de Itajubá

Rua Fernando Dias de Carvalho 38

35800-000 - Ferros - MG

Tiago Cézar Fonseca - tiagocezarf3141@gmail.com

Universidade Federal de Itajubá

Avenida Carlos de Paula Andrade 120

35900-206 - Itabira - MG

Victor Gabriel Santos Queiroz de Jesus - victorgab@gmail.com

Universidade Federal de Itajubá

Rua doutor Nelson de Sena 336

39705-000 - Sao Joao Evangelista - MG

Renata dos Santos - renatasantos@unifei.edu.br

Universidade Federal de Itajubá

Rua São Marcos 162

35930-116 - João Monlevade - MG

Resumo: Este artigo aborda a discussão sobre a importância da comunicação oral para a vida profissional do engenheiro, decorrente da formação plena nas universidades, além do cálculo. O principal objetivo é apresentar a relevância desse conceito para a engenharia, dado que grande parte dos jovens técnicos da área, na atualidade, não dominam a arte da oratória, apresentando problemas para socializar raciocínios e ideias e, consequentemente, gerando problemas para 
a empresa na qual estão empregados. Como revisão de literatura, são descritas as características fundamentais da comunicação oral, bem como sua relação com o estudo do cálculo, além de discutir métodos e esforços difundidos e promovidos, respectivamente, por especialistas e pelas instituições acadêmicas, para aprimorar essa competência. Diante disso, estabeleceu-se que a oralidade é fundamental para a formação profissional do engenheiro, e as universidades, já cientes disso, buscam formas diferenciadas para incentivar o exercício dessa competência. Apesar de tudo, ainda se mostra pouco eficiente, sendo necessário ampliar a quantidade de projetos universitários e, principalmente, conscientizar o discente sobre a importância dessa competência, a fim de evoluir, de forma mais eficaz, as habilidades orais comunicativas entre os estudantes e, por conseguinte, formar profissionais mais capacitados para o mercado de trabalho.

Palavras-chave: Comunicação. Oratória. Cálculo. Engenharia. Projetos de extensão. 


\section{A FORMAÇÃO PLENA DO ENGENHEIRO NAS UNIVERSIDADES, ALÉM DO CÁLCULO: A COMUNICAÇÃO ORAL COMO BASE PARA UM BOM PROFISSIONAL DA ENGENHARIA}

\section{INTRODUÇÃO}

$\mathrm{Na}$ atualidade, a atuação do profissional engenheiro vai além da habilidade de resolver equações matemáticas e solucionar problemas de engenharia - características do cálculo -, sendo necessária também a prática da comunicação, especialmente a comunicação oral. Diante disso, percebe-se que a realidade vigente ainda se apresenta pouco disseminada, uma vez que grande parte dos novos técnicos da área, apesar de disporem de amplo domínio sobre conhecimentos matemáticos e físicos, não manifestam grandes habilidades relacionadas à oralidade e, devido a isso, demonstram dificuldades nos processos seletivos profissionais. Do mesmo modo, um profissional que não exibe bons conhecimentos em cálculo, mesmo que possua elevado senso comunicativo, também dificilmente se tornará bem-sucedido profissionalmente.

Nesse contexto, depreende-se que há uma necessidade crescente para evoluir as técnicas e habilidades individuais de comunicação oral, haja vista a grande massa de engenheiros sem especialização comunicacional. Ademais, muitas universidades já se empenham para sanar essa imprescindibilidade, ao procurarem capacitar e qualificar tecnicamente os estudantes para o mercado de trabalho e para as exigências profissionais vigentes, a partir de trabalhos em equipe e projetos de extensão, além de atividades extracurriculares que promovem a socialização e, consequentemente, 0 desenvolvimento de competências comunicativas.

Isso posto, alguns questionamentos são importantes para a compreensão de tal contexto. Como é possível relacionar e interligar a comunicação oral e a prática do cálculo no contexto da engenharia? Como evoluir e aprimorar as capacidades individuais de comunicação? A partir dessas perguntas norteadoras, serão apresentadas discussões acerca da formação plena do profissional engenheiro, além do cálculo, bem como as formas de capacitação técnica para se comunicar bem, com enfoque nos esforços promovidos pelas universidades para corroborar o desenvolvimento dessa competência.

Como forma de embasar esses questionamentos, neste artigo consta uma revisão da literatura, fundamentada na obra de Bueno e Bilesky (2014), e apresenta conceitos e características, básicas e gerais, referentes aos termos "comunicação oral" e "cálculo", que respaldam esta pesquisa. Além disso, as obras de Flatley, Rentz e Lentz (2015), Watanabe et al. (2013) e Cândido (2007), bem como Feitosa et al. (2018) explicam, respectivamente, sobre a importância da comunicação para o profissional engenheiro, a especialização crescente da engenharia, a evolução individual e coletiva adquirida quando se pratica a comunicação oral e a importância do cálculo para a sociedade contemporânea, que são usadas como reforço aos argumentos verificados no trabalho alicerçado.

Outro ponto utilizado para fundamentar este artigo é a existência de técnicas e procedimentos para aprimorar as práticas de comunicação oral, divulgadas por Rodrigues (2014) e reforçadas por Barbosa (2019), Carneiro, Souza e Perosa (2017) e por Jaiswal ([2020]). As metodologias descritas, verificadas e difundidas pelos autores proporcionam, 
entre outros benefícios, mais eficiência ao se comunicar, ao permitir melhor fluidez, concisão e rapidez no modo como um indivíduo socializa uma informação.

Por fim, este artigo ainda reserva um espaço para sinalizar os esforços praticados e oferecidos pelas universidades no que tange à prática da comunicação oral para os estudantes. Entre eles, destaca-se a atuação do professor, como mediador das atividades dos discentes, e os projetos de extensão, os quais promovem, além do aprimoramento da oratória, evolução técnica e prática dos conceitos e conhecimentos adquiridos em sala de aula. Portanto, no decorrer deste artigo, será apresentada uma visão mais dinâmica e geral sobre a importância da comunicação oral para o profissional engenheiro, bem como a conexão entre essa competência e o exercício do cálculo na engenharia.

\section{A COMUNICAÇÃO ORAL}

A comunicação é a principal e primordial ferramenta humana utilizada para expressar pensamentos e ideias, experiências e sabedoria, proporcionando a evolução técnico-científica e filosófica em todos os campos do conhecimento. Em especial, a comunicação oral possui grande destaque, pois é a partir dela que profissionais das mais diversas áreas de estudo e trabalho precisam divulgar e relatar informações para colegas e outros indivíduos. Flatley, Rentz e Lentz (2015, p. 3) apontam o dom da comunicação como "[...] a característica mais desejável [...]" em um candidato ao se iniciar a carreira profissional. A mesma obra ainda abarca um pequeno trecho de uma entrevista com o gerente do setor de corretagem da Seaton Realty Group, David M. Seaton, o qual revela que "[...] a capacidade de se comunicar de forma eficaz [...] é essencial em todos os setores e necessária em todos os tipos de canais de comunicação. Afinal, ela é o diferencial na formação da percepção dos profissionais" (FLATLEY; RENTZ; LENTZ, 2015, p. 4).

Atualmente, a comunicação oral possui imensa importância para o profissional engenheiro, se comparado a épocas anteriores, uma vez que, de acordo com Watanabe et al. (2013, p. 2), a evolução da engenharia se encontra voltada para a "especialização crescente", ou seja, os requisitos para se tornar um bom técnico da área agregaram, com o passar dos anos, devido ao avanço industrial, a competência técnica, a qualificação científica e as competências gerenciais, sendo incorporada agora, devido ao "processo de globalização da economia e das empresas", a proficiência em comunicação. Com relação a isso, os autores ainda apontam que a formação profissional em engenharia vai muito além da base teórica e técnica acumulada no ensino superior, sendo necessário o desenvolvimento de atributos e habilidades não técnicas, dentre eles a capacidade da comunicação oral, o que se revela tão fundamental quanto o domínio sobre outras disciplinas, como o Cálculo.

Ademais, o dom da comunicação, como característica obrigatória para a engenharia, é utilizado pelos profissionais da área para socializar pensamentos e ideias, estes empregados na resolução de problemas, da melhor maneira possível, permitindo o entendimento geral da informação por qualquer pessoa, independentemente da experiência dela no assunto. De acordo com Bueno e Bilesky (2014, p. 3):

A engenharia não existiria sem a comunicação, porque tudo o que ela desenvolve precisa ser comunicado no meio técnico e em outros meios também. De nada adianta o avanço da tecnologia, se ela não for traduzida para uma linguagem acessível a todos que dela se utilizam. 
Outro fato que torna a interação social, baseada na comunicação oral, um dos conceitos mais relevantes e significativos tanto para um estudante quanto para um profissional da área de engenharia é o compartilhamento de conhecimentos, principalmente em meios cooperativos e colaborativos (grupos e equipes), a partir da oralidade que transforma e evolui a compreensão dos participantes sobre 0 assunto discutido. Segundo Cândido (2007, p. 15):

[...] em matemática, a comunicação tem um papel fundamental para ajudar os alunos a construírem um vínculo entre suas noções informais e intuitivas e a linguagem abstrata e simbólica da matemática. Se os alunos forem encorajados a se comunicar matematicamente com seus colegas, com o professor ou com os pais, eles terão oportunidade para explorar, organizar e conectar seus pensamentos, novos conhecimentos e diferentes pontos de vista sobre um mesmo assunto.

Diante desse cenário, verifica-se que a comunicação, definida como a capacidade, ação ou efeito de trocar, discutir e compartilhar ideias e informações, é essencial na capacitação técnica de qualquer indivíduo, ressaltando-se a engenharia. Esta, baseada apenas nas ciências naturais e exatas, sem enfoque no estudo das ciências da informação e comunicação, constitui um ensino falho e incompleto, alheio à realidade profissional vigente. Ademais, o estudo do cálculo deve sempre ser acompanhado pela prática comunicativa entre os estudantes, haja vista que a comunicação oral promove e facilita a constituição e evolução do conhecimento pessoal.

\section{CÁLCULO E COMUNICAÇÃO ORAL}

A prática do cálculo e da comunicação oral apresenta irrefutável conexão em relação às situações cotidianas vivenciadas por um profissional engenheiro, pois a carência de interação e contato entre colegas de trabalho causa prejuízos e perturbações para o desenvolvimento de projetos, especialmente quando em equipe, mesmo que os pensamentos, as ideias e questões desenvolvidas e abordadas fossem brilhantemente aplicados à realidade da empresa ou instituição. De acordo com Bueno e Bilesky (2014, p. 2):

Facilmente observamos que uma pequena falha na comunicação cria algumas dificuldades ou até mesmo decisões erradas, gerando prejuízos. Isso pode ainda acabar em conflitos pessoais entre empregados e empregadores ou uma equipe podendo se tornar ainda mais prejudicial. [...]. Podemos presenciar que existe constantemente um grande acúmulo de perdas e prejuízos devido a falta de uma boa comunicação na Engenharia.

Ademais, existem situações em que um engenheiro formula, eximiamente e de máxima excelência, teorias, pensamentos e ideias, inovadoras e revolucionárias, voltadas para resolução de problemas e incógnitas de cenários e circunstâncias reais e práticas do cotidiano. Entretanto, este indivíduo não consegue transmitir seu conhecimento de forma eficiente e clara para os outros, invalidando assim todo seu trabalho e esforço. Em relação a isso, Bazzo e Pereira (2006, p. 45) comentam que:

Um profissional eficiente é, antes de mais nada, aquele que sabe utilizar os seus conhecimentos, a sua memória, o seu raciocínio e a sua capacidade de pesquisar. Mas também é aquele que sabe se expressar, comunicando 
com eficácia idéias e resultados de seu trabalho. Uma boa solução presa na cabeça de seu criador é praticamente inútil.

Dada a ligação entre esses dois conceitos, vale ressaltar a importância deles para o profissional engenheiro. Sendo assim, a comunicação oral é denominada peça fundamental para a engenharia quando se considera a necessidade de compartilhar e tornar acessível o conhecimento técnico sobre determinados assuntos, além de permitir maior evolução e desenvolvimento intelectual no meio acadêmico ao se praticar o trabalho em equipe e discussões em grupo. Neste ínterim, o cálculo, como instrumento matemático universalmente utilizado, demonstra especial destaque na conjuntura atual, pois permite o engenho de "[...] estruturas e dispositivos que transformam recursos naturais em formas adequadas visando sempre avanços tecnológicos que melhorem as necessidades humanas e a qualidade de vida das pessoas" (FEITOSA et al., 2018, p. 21). Desse modo, observa-se que, apesar da evidente relevância e influência do ensinamento do cálculo na engenharia, é importante que haja o estudo e a prática da comunicação oral por um profissional da engenharia, pois, como citado por Bueno e Bilesky $(2014$, p. 1), o atual momento é :

[...] identificado por pensadores modernos de "A Era da informação", onde a comunicação é o meio mais eficaz de aprender, ensinar e realizar suas tarefas no seu cotidiano. Um bom engenheiro que não consegue ter uma boa comunicação certamente encontrará grandes obstáculos na sua carreira profissional.

Corroborando tal abordagem está o posicionamento de Carneiro, Souza e Perosa (2017), para os quais a era da informação exige um engenheiro eficiente, que utilize clássicos e novos instrumentos além da memória, do raciocínio e da capacidade de pesquisar. Tudo isso deve estar, principalmente, relacionado à habilidade de expressar, com clareza, os resultados, as soluções e os objetivos propostos.

Portanto, observa-se que o estudo do cálculo está diretamente ligado ao estudo e prática da comunicação oral, ou seja, são inseparáveis e devem ser comumente praticados durante o período acadêmico e também após essa fase, mantendo assim o nível de eficiência e de preparo mental do profissional engenheiro em qualquer setor do mercado de trabalho e em qualquer momento da vida.

\section{$4 \quad$ PRÁTICAS DE COMUNICAÇÃO ORAL}

Diante das análises e discussões acerca da importância da comunicação oral para os engenheiros, descobriu-se a forte conexão entre essa competência e a capacidade de realizar cálculos e resolver problemas matemáticos e físicos. Desse modo, dois questionamentos nortearam essa discussão, a saber: a) como é possível aprimorar as práticas de comunicação oral?; b) como as universidades de engenharia promovem as práticas de comunicação oral?

Dado isso, na primeira parte, concentra-se a discussão sobre maneiras de evoluir e aprimorar as capacidades de comunicação oral individualmente, a partir de reflexões pessoais sobre o modo como o indivíduo se comunica. Entre os argumentos citados, encontram-se as técnicas difundidas por Rodrigues (2014) e o método dos "7Cs da comunicação", citado por Jaiswal ([2020]) em seu artigo sobre as características e os tipos de comunicação.

$\mathrm{Na}$ segunda parte, debatem-se os esforços promovidos pelas universidades de engenharia para promover e proporcionar ambientes e experiências que permitam o 
desenvolvimento teórico e prático do estudante, com enfoque nos projetos de extensão. Entre os argumentos utilizados, encontra-se a atuação dos professores para concretização desse objetivo e a conceituação e caracterização dos projetos de extensão, com foco no programa SAE Brasil (PROGRAMAS..., [200-]). Entretanto, além dessa proposta extracurricular específica, existem diversas outras atividades complementares oferecidas pelas instituições acadêmicas, com destaque, dentre outros, para iniciação científica, projetos de extensão, voluntariado, visitas técnicas, trabalhos em equipe, monitorias e atividades empreendedoras (CONSELHO NACIONAL DE EDUCAÇÃO, 2019).

\subsection{Formas de aprimoramento das práticas de comunicação oral}

Devido ao cotidiano uso e à prática contínua da comunicação pelo engenheiro, é interessante para o profissional da área aprimorar essa qualidade e torná-la mais eficiente e direta. Para tanto, baseando-se em abordagens como a de Matos (2009), Rodrigues (2014) divulgou técnicas de oratória divididas em uma série de etapas e estágios para alcançar esse objetivo, a saber: ter meta, incluir o interlocutor, manter o respeito, perguntar mais, escutar de verdade, ficar atento ao tom, zelar pela linguagem corporal, fazer críticas objetivas, argumentar com exemplos, ser menos adversativo, evitar ficar na defensiva, saber ficar em silêncio e praticar a empatia.

Ao estabelecer metas, deve-se pensar no resultado antes de iniciar uma conversa, proporcionando foco e rapidez. Quanto à inclusão do interlocutor no assunto, é importante que isso seja feito com o uso do pronome "nós" na frase, tornando o ouvinte/ falante mais atento e interessado na conversa. Para manter o respeito, os argumentos do interlocutor devem ser levados em consideração além de estar aberto a ouvir e manter a firmeza, mas evitar a agressividade. Outro ponto importante é perguntar mais, ou seja, por meio de questionamentos, é preciso tentar abranger a perspectiva do interlocutor sobre o assunto. $\mathrm{E}$ se perguntou, principalmente, é necessário que se escute de verdade, prestando atenção ao assunto desenvolvido pelo comunicador, sem interrompê-lo. É primordial que o tom da fala seja considerado atentamente, evitando o uso de sarcasmo e ironia, pois essa forma de se comunicar transmite conotação de deboche. Os interlocutores devem estar atentos à linguagem corporal, mostrando coerência entre a fala e os movimentos do corpo. Ao fazer críticas, que sejam objetivas e impessoais, evitando julgamentos sobre a pessoa. Para argumentar, que sejam explorados os exemplos e as histórias, os quais reforçam e comprovam os argumentos. No intuito de ser menos adversativo, é mais agradável construir frases dando preferência à conjunção "e" e não à conjunção "mas". É importante também não ficar tanto na defensiva, ou seja, o mais viável é adotar postura assertiva e fazer perguntas para explorar os diferentes pontos de vista. Sempre que possível, é interessante suspender a fala por alguns momentos para proporcionar reflexão, ou seja, saber ficar em silêncio. Ao praticar a empatia, deve-se se fazer entender e imaginar o ponto de vista do interlocutor sobre determinado assunto.

Em relação a tais técnicas, Barbosa (2019) reforça que, para uma comunicação oral eficiente, é necessário ter conhecimento sobre o assunto discutido, ser franco e claro (sem desvios) e modelar a forma de comunicação, além de prestar atenção na linguagem oral e corporal, o que permite mais fluidez e clareza das informações socializadas. Além disso, é de grande importância o uso e prática da empatia, a fim de compreender os principais pontos de vista dos tópicos levantados na conversa.

Outro método bastante utilizado e difundido é o chamado "7Cs da comunicação", que apresenta sete termos relacionados à evolução e aprimoramento das técnicas de comunicação oral, determinando características de uma comunicação de excelência. De acordo com Jaiswal ([2020]), as sete palavras que nomeiam esse método são: coerência, 
clareza, completude, concisão, concretude, correção e cortesia. Desse modo, a autora busca demonstrar que, ao se praticar esses sete pontos, o interlocutor garante a transmissão de uma ideia clara e detalhada, tornando-a de fácil entendimento, a partir de um tipo específico de comunicação, correto à audiência, e de foco no objetivo da conversa, seguindo um raciocínio lógico e completo, mostrando empatia para com seus ouvintes.

Portanto, as orientações supracitadas, presentes também em outros estudos, permitem que qualquer indivíduo pratique e desenvolva o dom da comunicação oral, a qual favorece a compreensão do que é falado, poupando tempo e permitindo uma interação mais rápida e eficaz entre o comunicador e o ouvinte.

\subsection{Práticas de comunicação oral nas universidades de engenharia}

A prática da comunicação oral pode ser entendida como um processo de argumentação científica e metodológica no meio acadêmico, a qual estimula o desenvolvimento do raciocínio e do intelecto dos estudantes quando é exercitada em sala de aula. De acordo com Suzuki e Zompero (2016, p. 104):

[...] a argumentação decorre do levantamento de hipóteses, da análise dos dados e evidências coletadas, além da avaliação da investigação, consolidando as justificativas levantadas a ponto de validar a teoria ou refutá-la, concluindo a investigação da questão proposta.

Nesse contexto, afirma-se que a argumentação ocorre em vários contextos, mas é pela educação sistematizada, a partir do papel mediador do docente, que os argumentos, principalmente os científicos, são desenvolvidos (SUZUKI; ZOMPERO 2016). Isso significa que a prática da comunicação oral, como instrumento de aprendizado e evolução das competências e habilidades individuais, é fomentada, primordialmente, pelo professor, a partir de atividades variadas e bem construídas que permitam o exercício da argumentação e desenvolvimento de conhecimentos. Em complemento a isso, Oliveira et al. (2018) revelam que:

A relação verticalizada, onde o professor transmite as informações e os estudantes as absorvem, deve dar lugar à troca de visões, em que o docente assume o papel de condutor do ensino como facilitador, tirando dúvidas, aprofundando o tema e estimulando o debate, de forma a proporcionar ao estudante um aprendizado mais amplo e completo.

Baseado nisso, percebe-se grande preocupação das universidades, principalmente aquelas com o ensino voltado para a engenharia, em promover, por parte dos docentes, estudos mais dinâmicos e eficientes, que impulsionam a argumentação científica e metodológica do indivíduo, além de possibilitar a interação social entre os alunos e proporcionar, consequentemente, o aprimoramento das práticas de comunicação oral.

$\mathrm{Na}$ atualidade, a formação e capacitação plena do engenheiro não exigem apenas a base de estudos teóricos e conceituais oferecidos nas universidades, sendo necessário também uma gama de competências adicionais voltadas à prática da engenharia em diversos setores. De acordo com Abrão (2015, p. 101):

Um conjunto respeitável de competências, habilidades e qualidades, transversais às competências técnicas, juntamente com uma formação geral com fortes bases conceituais são cada vez mais centrais na formação dos estudantes nas universidades. Esses dois eixos são 
fundamentais na formação universitária necessária para o mundo do trabalho no século XXI e aparecem como área de intersecção nas diretrizes curriculares dos cursos de graduação do enfoque das competências e habilidades gerais.

Além disso, Abrão (2015) cita que a universidade deve vincular ensino, pesquisa e extensão, a fim de formar o sujeito competente, crítico, reflexivo e criativo, capaz de perceber as mudanças sociais. Não obstante, deve saber vincular tudo isso ao saber profissional de forma a ter condições de atuar nos problemas com responsabilidade e visão cidadã.

À vista disso, um dos principais e fundamentais exemplos de atividades complementares e extracurriculares, para evolução dos conhecimentos adquiridos em sala e oferecidos nas universidades, são os projetos de extensão. Eles proporcionam experiências reais da rotina de um engenheiro e permitem aos estudantes trabalharem e aprimorarem, de forma prática, as habilidades e competências teóricas adquiridas durante o período acadêmico, relacionadas principalmente ao cálculo e à física, além da comunicação oral. Segundo Bamberg (2006, p. 55), os projetos de extensão propiciam aos alunos:

[...] a interação dos alunos de engenharia com colegas com diferentes formações, com profissionais de empresas de engenharia e principalmente com os operários, profissionais com quem irão lidar no exercício de sua profissão, em uma situação em que são criadas experiências difíceis de se repetirem, possibilitando uma troca muito rica entre as partes.

Ademais, Bamberg (2006, p. 55) destaca que os envolvidos complementam "[...] sua formação acadêmica através de atividades de ensino que possibilitam o aprimoramento de sua capacidade de comunicação oral e escrita". Tal abordagem demonstra que os projetos de extensão, além de proporcionar contato e experiência dos alunos com a realidade da profissão escolhida e permitir o aprimoramento de habilidades e competências fundamentais para o profissional da área, propicia o desenvolvimento das práticas de comunicação oral, sendo, portanto, imprescindível na formação do discente durante o período acadêmico.

Diante do exposto, a SAE Brasil, como uma das principais instituições responsáveis pelos projetos de extensão em engenharia, apresenta diversas opções para os estudantes, e de acordo com o site oficial da entidade (PROGRAMAS..., [200-]), os principais projetos voltados para o meio acadêmico são:

a) Fórmula SAE: programa que permite o contato do estudante com a construção de um veículo tipo Fórmula e a experiência em ambientes de trabalho em equipe, voltada para competição;

b) Baja SAE: programa que permite o contato do aluno com a construção de um veículo off-road, desde o design do projeto até o desenvolvimento e estruturação do automóvel, voltado para competição;

c) Aerodesign SAE: programa que proporciona compartilhamento de conhecimentos sobre Engenharia Aeronáutica entre os discentes, com a construção de aeromodelos voltados para competição entre equipes.

Portanto, é perceptível a evolução e os desenvolvimentos técnico e prático proporcionados pelas atividades complementares, oferecidas pelas universidades aos discentes no que tange à experiência e conhecimentos adquiridos. Além disso, esses programas, com ênfase nos projetos de extensão, promovem a evolução da comunicação 
oral, pois as atividades citadas disponibilizam ambientes e vivências diversificadas, bem como concedem maior interação entre os alunos.

\section{CONSIDERAÇÕES FINAIS}

As discussões, no decorrer deste artigo, relacionadas à importância da comunicação oral para o profissional engenheiro sinalizaram que, além da prática e entendimento dos conceitos e ferramentas matemáticas, ou seja, além do cálculo, existem outras habilidades relevantes para serem aprendidas, aprimoradas e continuamente exercitadas pelos estudantes de engenharia, em especial a comunicação oral. Esta, inerentemente a qualquer outra competência qualificativa, induz aos diferenciais técnico e prático do profissional engenheiro em relação aos seus concorrentes, pois evidencia melhor capacitação científica, tecnológica e social no que tange ao trabalho em equipe e ao compartilhamento de informações, raciocínios, pensamentos e ideias.

Dado isso, como resposta ao primeiro questionamento que norteou o desenvolvimento deste estudo - como é possível relacionar e interligar a comunicação oral e a prática do cálculo no contexto da engenharia? -, entende-se que a comunicação, especialmente a oral, permite a transmissão de informações em sua totalidade de modo prático e direto, e consequentemente proporciona mais facilidade aos engenheiros no que tange ao compartilhamento de teorias e raciocínios matemáticos. Além disso, a oralidade faz parte do cotidiano do técnico engenheiro, sendo necessário, portanto, praticar e exercitar a oratória, a fim de manter uma comunicação simples e eficiente, evitando possíveis desastres e prejuízos.

Ademais, em relação à segunda interrogatória - como evoluir e aprimorar as capacidades individuais de comunicação? -, existem duas abordagens: uma relacionada ao individual e outra, ao acadêmico. Em relação à capacitação particular (do próprio indivíduo), existem diversas pesquisas e técnicas amplamente difundidas entre profissionais das mais diversas áreas de estudo, que descrevem o comportamento adequado de um indivíduo em meio a uma conversa, como prestar atenção nos argumentos alheios e discutir de forma respeitosa e amigável, bem como falar de modo conciso, correto, coerente e completo. Outrossim, no âmbito acadêmico, existem projetos e atividades extracurriculares oferecidos pelas universidades que buscam desenvolver habilidades relacionadas às práticas da comunicação oral, como os projetos de extensão, grande parte deles organizados pela SAE Brasil (PROGRAMAS..., [200-]).

Desse modo, por ser fundamental para o profissional da engenharia, é necessário o desenvolvimento de mais programas e projetos que proporcionem e aprimorem a capacidade de comunicação dos discentes a partir da oratória, além de conscientizá-los sobre essa importância, a fim de evoluir, de forma mais eficaz, as competências orais comunicativas entre os estudantes e, consequentemente, formar profissionais mais capacitados para o mercado de trabalho.

\section{REFERÊNCIAS}

ABRÃO, Mariangela. A importância das atividades complementares na formação do aluno da graduação. 2015. Tese (doutorado) - Universidade Estadual de Campinas, Faculdade de Educação, Campinas, 2015. Disponível em:

http://www.repositorio.unicamp.br/handle/REPOSIP/254067. Acesso em: 6 abr. 2021.

BAMBERG, Paula. Um programa social de extensão como espaço de formação de alunos de engenharia. In: CONGRESSO BRASILEIRO DE ENSINO DE ENGENHARIA, 34., 
2006, Passo Fundo. Anais [...]. Passo Fundo: Abenge, 2006. p. 50-57. Disponível em: http://www.abenge.org.br/cobenge/arquivos/13/artigos/10_192_270.pdf. Acesso em: 4 mar. 2021.

BARBOSA, Suria. 5 passos para desenvolver sua habilidade de comunicação. Estudar na prática, [s. I.], 19 set. 2019. Disponível em: https://www.napratica.org.br/desenvolverhabilidade-de-comunicacao/. Acesso em: 19 abr. 2021.

BAZZO, Walter Antonio; PEREIRA, Luiz Teixeira do Vale. Comunicação. In: BAZZO, Walter Antonio; PEREIRA, Luiz Teixeira do Vale. Introdução à engenharia: Conceitos, Ferramentas e Comportamentos. Florianópolis: Editora da UFSC, 2006. cap. 2, p. 43-61. Disponível em:

https://www.academia.edu/33612414/Introdu

\%C3\%A7\%C3\%A3o_a_engenharia_Walter_Antonio_Bazzo. Acesso em: 6 abr. 2021.

BUENO, Marcio Oliveira, BILESKY, Luciano Rossi. A importância da comunicação na engenharia. Fait, Itapeva, n. 2, maio 2014. Disponível em:

http://fait.revista.inf.br/imagens_arquivos/arquivos_destaque/vFJRhvQuFmilfjP_2014-422-20-8-33.pdf. Acesso em: 16 mar. 2021.

CÂNDIDO, Patrícia T. Comunicação em Matemática. In: SMOLE, Kátia Stocco; DINIZ, Maria Ignez (org.). Ler, escrever e resolver problemas: Habilidades básicas para aprender matemática. Porto Alegre: Artmed, 2007. cap. 1, p. 15-28. Disponível em: https://statics-americanas.b2w.io/sherlock/books/firstChapter/185649.pdf. Acesso em: 2 abr. 2021.

CARNEIRO, Maísa Gomes; SOUZA, João Gabriel Campos; PEROSA, Vinícius. A importância da comunicação na Engenharia. In: CONGRESSO BRASILEIRO DE ENGENHARIA DE PRODUÇÃO, 7., 2017, Ponta Grossa. Anais [...]. Ponta Grossa: APREPRO, 2017. Disponível em: http://anteriores.aprepro.org.br/conbrepro/2017/down.php?id=3426\&q=1. Acesso em: 2 abr. 2021.

CONSELHO NACIONAL DE EDUCAÇÃO. Resolução nº 2, de 24 de abril de 2019. Institui as Diretrizes Curriculares Nacionais do Curso de Graduação em Engenharia. In: CONSELHO NACIONAL DE EDUCAÇÃO. Atos Normativos: Súmulas, Pareceres e Resoluções: Resoluções do CNE. Brasília, DF: Ministério da Educação, 2019. Disponível em: http://portal.mec.gov.br/index.php? option=com_docman\&view=download\&alias=112681-rces002-19\&category_slug=abril2019-pdf\&ltemid=30192. Acesso em: 28 mar. 2021.

FEITOSA, Cairo et al. Qual a importância do cálculo ao longo dos tempos? Campo do Saber, João Pessoa, v. 4, n. 3, p. 21, abr. 2018. Disponível em: http://periodicos.iesp.edu.br/index.php/campodosaber/article/view/131. Acesso em: 18 mar. 2021.

FLATLEY, Marie; RENTZ, Kathryn; LENTZ, Paula. Comunicação empresarial. Tradução: Félix José Nonnenmacher. 2. ed. Porto Alegre: AMGH Editora Ltda., 2015.

JAISWAL, Babita. Communication: Concept and Types. Lucknow: Department of Library 
\& Information Science, [2020]. Disponível em:

https://www.lkouniv.ac.in/site/writereaddata/siteContent/202004032240236202babita_jais_ Communication_concept_and_types.pdf. Acesso em: 3 abr. 2021.

MATOS, Gustavo Gomes de. Comunicação empresarial sem complicação: como facilitar a comunicação na empresa, pela via da cultura e do diálogo. 2. ed. rev. e ampl. Barueri: Manole, 2009.

OLIVEIRA, Bruno Luciano Carneiro Alves de et al. Team-Based Learning como Forma de aprendizagem Colaborativa e Sala de Aula Invertida com Centralidade nos Estudantes no Processo Ensino-Aprendizagem. Rev. bras. educ. med. Brasília, DF, v. 42, n. 4, p. 86-95, Oct./Dec. 2018. Disponível em: https://www.scielo.br/pdf/rbem/v42n4/1981-5271-rbem-424-0086.pdf. Acesso em: 6 abr. 2021.

PROGRAMAS Estudantis. SAE Brasil, [s. I., 200-]. Disponível em:

https://saebrasil.org.br/programas-estudantis/. Acesso em: 14 abr. 2021.

RODRIGUES, Anna Carolina. 13 soluções para melhorar a comunicação. Revista Online Exame, [s. I.], 21 ago. 2014. Disponível em: https://exame.com/carreira/13-solucoes-paramelhorar-a-comunicacao/. Acesso em: 19 mar. 2021.

SUZUKI, Wanessa H. Pickina Silva; ZOMPERO, Andreia de Freitas. O desenvolvimento do argumento e o aprimoramento dos aspectos semânticos e pragmáticos da linguagem oral, mediante o ensino por investigação. Góndola,Enseñ Aprend Cienc, v. 11, n. 1, p. 100-116, Enero/Jun. 2016. Disponível em:

https://revistas.udistrital.edu.co/index.php/GDLA/article/view/10201/11557. Acesso em: 4 mar. 2021.

WATANABE, Flávio Yukio et al. Iniciação à engenharia e à metodologia de pesquisa e redação científica. In: CONGRESSO BRASILEIRO DE EDUCAÇÃO EM ENGENHARIA, 41., 2013, Gramado. Anais [...]. Gramado: Abenge, 2013. Disponível em: https://turing.pro.br/anais/COBENGE-2013/pdf/117911_1.pdf. Acesso em: 17 mar. 2021.

\title{
THE FULL FORMATION OF ENGINEERS IN UNIVERSITIES, BEYOND CALCULUS: THE ORAL COMMUNICATION AS BASE FOR A GOOD PROFESSIONAL ENGINEER
}

\begin{abstract}
This article discusses the importance of oral communication to engineer's professional life and is delimited to the topic related to the full formation of it in universities, beyond calculus. The main objective is to present the relevance of this concept to engineering, given that great number of young technicians in this area, currently, can't command the art of oratory, presenting problems to transmit reasonings and ideas, and therefore, creating losses for the company in which they are employed. As a literature review, this work describe the basic characteristics of oral communication, as well as its connection to calculus' learning, besides discuss diffused and promoted methods and efforts, respectively, of specialists and academic institutions, to perfect this competency. Therefore, it was established that orality is fundamental for the professional training of the engineer, and universities, already aware of this, seek different ways to encourage the
\end{abstract}


exercise of this competence. In spite of everything, it is necessary to increase the number of university projects and, mainly, to make students aware of the importance of this competence, in order to evolve, in a more effective way, the oral communicative skills among students and, therefore, training more qualified professionals for the job market.

Keywords: Communication. Oratory. Calculus. Engineering. Extension project. 